\title{
Synthesis and Characterization of Silver Nanoparticles Using Cannonball Leaves and Their Cytotoxic Activity against MCF-7 Cell Line
}

\author{
Preetha Devaraj, ${ }^{1}$ Prachi Kumari, ${ }^{1}$ Chirom Aarti, ${ }^{1}$ and Arun Renganathan ${ }^{2}$ \\ ${ }^{1}$ Department of Biotechnology, Faculty of Science Humanities, SRM University, Kattankulathur 603 203, Chennai, \\ Tamil Nadu, India \\ ${ }^{2}$ Department of Biomedical Science, School of Basic Medical Sciences, Bharathidasan University, Tiruchirappalli 620024 , \\ Tamil Nadu, India \\ Correspondence should be addressed to Preetha Devaraj; preethad06@gmail.com
}

Received 7 May 2013; Accepted 8 July 2013

Academic Editor: Hongmei Luo

Copyright (C) 2013 Preetha Devaraj et al. This is an open access article distributed under the Creative Commons Attribution License, which permits unrestricted use, distribution, and reproduction in any medium, provided the original work is properly cited.

\begin{abstract}
Cannonball (Couroupita guianensis) is a tree belonging to the family Lecythidaceae. Various parts of the tree have been reported to contain oils, keto steroids, glycosides, couroupitine, indirubin, isatin, and phenolic substances. We report here the synthesis of silver nanoparticles (AgNPs) using cannonball leaves. Green synthesized nanoparticles have been characterized by UV-Vis spectroscopy, SEM, TEM, and FTIR. Cannonball leaf broth as a reducing agent converts silver ions to AgNPs in a rapid and ecofriendly manner. The UV-Vis spectra gave surface plasmon resonance peak at $434 \mathrm{~nm}$. TEM image shows well-dispersed silver nanoparticles with an average particle size of $28.4 \mathrm{~nm}$. FTIR showed the structure and respective bands of the synthesized nanoparticles and the stretch of bonds. Green synthesized silver nanoparticles by cannonball leaf extract show cytotoxicity to human breast cancer cell line (MCF7). Overall, this environmentally friendly method of biological silver nanoparticles production provides rates of synthesis faster than or comparable to those of chemical methods and can potentially be used in various human contacting areas such as cosmetics, foods, and medical applications.
\end{abstract}

\section{Introduction}

Couroupita guianensis, whose common names include ayahuma and the cannonball tree, is an evergreen tree allied to the Brazil nut (Bertholletia excelsa) and is native to tropical northern South America and to the southern Caribbean. As per textual record, the tree has been growing for the past three thousand years in India. The cannonball tree possesses many medicinal properties such as antibiotic, antifungal, antiseptic, and analgesic qualities. Extracts of this tree were used to cure colds and stomach aches. Juice made from the leaves is used to cure skin diseases and malaria. The inside of the fruit can disinfect wounds and young leaves ease toothache. The fruit emits an unpleasant odour and can be used as an insect repellent just by rubbing it to the skin or clothes $[1,2]$. Overall the tree possesses skin fibroblast proliferation, antioxidant [3, 4], antihelmintic [5], wound healing, antimicrobial, and antinociceptive [1] activities.

Nanotechnology is significant on account of its preeminence upon the comprehension, use, and control of matter at magnitudes of a minute scale, akin to approaching atomic levels, with which to manufacture new substances, instruments, and frameworks [6]. The synthesis of nanocrystals is in the limelight in modern nanotechnology. Biosynthesis of nanoparticles by plant extracts is currently under exploitation [7]. Nanotechnology is currently employed as a tool to explore the darkest avenues of medical sciences in several ways like imaging [8], sensing [9], targeted drug delivery [10], gene delivery systems [11], and artificial implants [12].

In present situation, silver nanoparticles (AgNPs) are in great use in the medicinal, pharmaceutical, agricultural industry and in water purification. These nanoparticles can 
be synthesized either chemically or biologically. But the chemical process for synthesis of silver nanoparticles is more elaborate and leaves behind toxic effect that adversely affects the ecosystem. On the other hand, biological synthesis of silver nanoparticles is less time consuming, less costly, and more ecofriendly; therefore, in recent time, scientists are looking forward to the possible biological methods for the synthesis of silver nanoparticles [13]. AgNPs have unique optical, electrical, and thermal properties and are being incorporated into products that range from photovoltaics to biological and chemical sensors. Examples include conductive inks, pastes, and fillers which utilize silver nanoparticles for their high electrical conductivity, stability, and low sintering temperatures; in addition, AgNPs are applied in molecular diagnostics and photonic devices. An increasingly common application is the use of silver nanoparticles for antimicrobial coatings, and many textiles, keyboards, wound dressings, and biomedical devices now contain silver nanoparticles that continuously release a low level of silver ions to provide protection against bacteria. In the present study, the green synthesis of silver nanoparticles from the cannonball leaf extract has been carried out and characterized by UV-Vis spectra, SEM, TEM, and FTIR analysis. The cytotoxicity activity of synthesized AgNPs against MCF-7 breast cancer cell line was determined.

\section{Experimental}

2.1. Preparation of Leaf Extract for Silver Nanoparticles. Cannonball leaves were collected and washed twice with distilled water and dried at $40^{\circ} \mathrm{C}$. Dried leaves were finely powdered in an electric grinder and stored at room temperature in an airtight container till further use.

2.1.1. Aqueous Extract. Ten grams of dried powder of cannonball leaves was added to $100 \mathrm{~mL}$ of distilled water and stirred for $6 \mathrm{~h}$ at slow heat. Every two hours the contents were filtered through eight layers of muslin cloth, and the filtrate was centrifuged at $5000 \mathrm{rpm}$ for $15 \mathrm{~min}$. This process was repeated twice, and the supernatant was pooled and concentrated by using a rotary vacuum evaporator at reduced pressure. The concentrated extract was sterilized and stored at $4^{\circ} \mathrm{C}$.

2.1.2. Solvent Extract. Ten grams of dried powder of cannonball leaves was extracted with $100 \mathrm{~mL}$ of ethanol, acetone, petroleum ether, and chloroform, respectively, kept on a rotator shaker at 190-220 rpm for $24 \mathrm{~h}$. The contents were filtered through eight layers of muslin cloth and the filtrate was centrifuged at $5000 \mathrm{rpm}$ for $15 \mathrm{~min}$. This process was repeated twice, and the supernatant was pooled and concentrated by using a rotary vacuum evaporator at reduced pressure. The concentrated extract was sterilized and stored at $4^{\circ} \mathrm{C}$ till further studies.

2.2. Synthesis of AgNPs. The synthesis of silver nanoparticles was done by mixing cannonball leaf extract and $1 \mathrm{mM}$ of aqueous silver nitrate solution $\left(\mathrm{AgNO}_{3}\right)$ in the ratio $1: 10$ and heated at $80^{\circ} \mathrm{C}$ until the color of the solution was changed from brown to reddish brown. At this point the solution was cooled to room temperature and centrifuged at $5000 \mathrm{rpm}$ for 10 minutes. The supernatant was discarded and the pellet was air dried in the incubator.

2.3. Characterization of AgNPs. UV-absorption spectra of synthesized AgNPs by using cannonball leaf extract were measured using UV-visible spectrometer (Shimadzu UV2700). Scanning electron microscopy (SEM) analysis of synthesized AgNPs was done using a Hitachi S-4500 SEM machine. The size and shape of the synthesized AgNPs were determined by transmission electron microscopy (TEM). The TEM images of synthesized AgNPs were obtained by using TECHNAI 10 Philips. Prior to analysis, AgNPs were sonicated for 5 minutes, and a drop of appropriately diluted sample was placed onto a carbon-coated copper grid. The liquid fraction was allowed to evaporate at room temperature. Fourier transform infrared (FTIR) spectral measurements were carried out to identify the potential biomolecules in cannonball leaf extract which is responsible for reducing and capping the bioreduced silver nanoparticles.

2.4. Cytotoxicity of AgNPs. The cytotoxicity of synthesized AgNPs against MCF-7 cells was measured by MTT (3-(4, 5-dimethylthiazol-2-yl)-2, 5-diphenyl tetrazolium bromide) assay. The MTT assay is a colorimetric, nonradioactive assay for measuring cell viability through increased metabolization of tetrazolium salt [14]. MCF-7 cells were seeded at a density of $5 \times 10^{4}$ cells/well into 96 -well plates. Then, the cells were treated with different concentration of synthesized AgNPs $(0-100 ; \mu \mathrm{L} / \mathrm{mL})$ and incubated in the presence of $5 \% \mathrm{CO}_{2}$ and $95 \%$ humidity at $37^{\circ} \mathrm{C}$ for $24 \mathrm{~h}$. MTT $(5 \mathrm{mg} / \mathrm{mL})$ was added to the incubated cells, then incubated further for another $4 \mathrm{~h}$. The crystals were dissolved in $200 \mu \mathrm{L}$ of DMSO and the absorbance was measured colorimetrically at $570 \mathrm{~nm}$ with reference filter as $655 \mathrm{~nm}$.

\section{Results and Discussion}

In the present study, reduction of silver ions present in the aqueous solution of silver nitrate during the reaction with the ingredients of cannonball leaf extract has been seen by the UV-Vis spectroscopy ranging from 300 to $600 \mathrm{~nm}$. The maximum absorption was obtained at $440 \mathrm{~nm}$ (Figure 1). The bioreduction of $\mathrm{AgNO}_{3}$ ions in solution was monitored by periodic sampling of aliquots $(0.1 \mathrm{~mL})$ of aqueous component and measuring UV-Vis spectra of the solution. UV-Vis spectra show no evidence of absorption in the range of 400-800 nm for the plant extract (Figure 1(a)), and the plant extract solution exposed to $\mathrm{AgNO}_{3}$ ions shows a distinct absorption at around $434 \mathrm{~nm}$ (Figure 1(b)) which corresponds to surface plasmon resonance (SPR) of silver nanoparticles established at $420 \mathrm{~nm}$ in previous studies [15]. It is observed that the silver SPR band occurs initially at $430 \mathrm{~nm}$; after completion of the reaction, the wavelength of the SPR band stabilizes at $434 \mathrm{~nm}$. Green synthesized AgNPs were stable for six months without shifting the surface plasmon absorbance band [16, 17]. This 


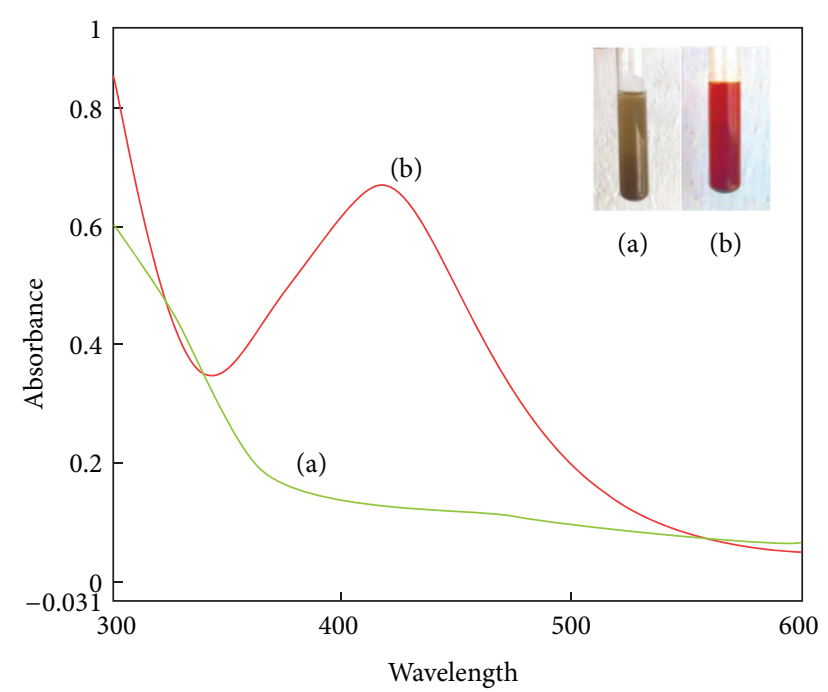

FIGURE 1: UV-Vis absorption spectrum of (a) cannonball leaf extract and (b) biosynthesized AgNPs.

suggests that the phytochemical present in cannonball leaves acts as a reducing agent.

SEM analysis shows high-density AgNPs synthesized by cannonball leaf extract (Figure 2). It was shown that relatively spherical and uniform AgNPs were formed with diameter of 13 to $61 \mathrm{~nm}$. The SEM image of silver nanoparticles was due to interactions of hydrogen bond and electrostatic interactions between the bioorganic capping molecules bound to the AgNPs. The nanoparticles were not in direct contact even within the aggregates, indicating stabilization of the nanoparticles by a capping agent [18]. The larger silver particles may be due to the aggregation of the smaller ones, due to the SEM measurements.

Figure 3 shows the TEM image of AgNPs synthesized by using cannonball leaf extract which predominates with spherical triangle, truncated triangles, and decahedral morphologies ranging from 25 to $40 \mathrm{~nm}$ with an average size of $28.40 \mathrm{~nm}$. Most of the AgNPs were roughly circular in shape with smooth edges. These structures were identical with those of the $\mathrm{Ag}$ nanoparticles produced from the extract prepared from leaves of Cinnamomum camphora and phyllanthin, which was attributed to a similarity in the reductive agents present in both plant species $[6,19]$. The phytochemical constituents in the cannonball leaves such as tannins, phenols, saponins, and flavonoids may act as reducing agents during the synthesis of AgNPs [20, 21].

The IR spectra provided information about the local molecular environment of the organic molecules on the surface of nanoparticle. In the present work, FTIR spectral measurements were carried out to identify the potential biomolecules in cannonball leaf extract which is responsible for reducing and capping the bioreduced silver nanoparticles. Fourier transform infrared spectroscopy (FTIR) is a technique which is used to analyze the chemical composition of many organic chemicals, polymers, paints, coatings, adhesives, lubricants, semiconductor materials, coolants, gases, biological samples, inorganics, and minerals. FTIR can be

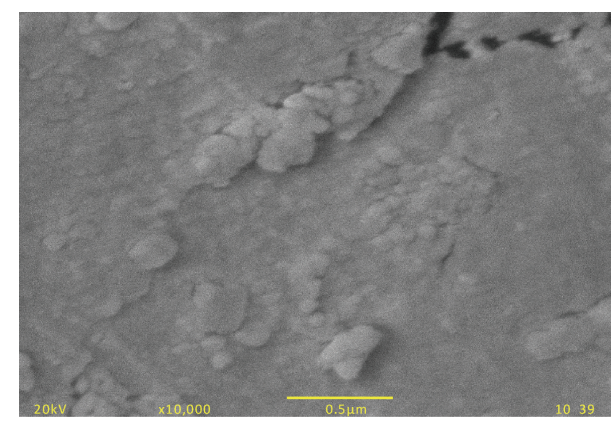

FIGURE 2: SEM micrograph of AgNPs synthesized from cannonball leaf extract.

used to analyze a wide range of materials in bulk or thin films, liquids, solids, pastes, powders, fibres, and other forms. FTIR analysis can give not only qualitative (identification) analysis of materials, but, with relevant standards, can be used for quantitative (amount) analysis. FTIR can be used to analyze samples up to $\sim 11$ millimetres in diameter and either measure in bulk or the top $\sim 1$ micrometer layer. FTIR measurements were carried out to identify the possible biomolecules responsible for capping and efficient stabilization of the metal nanoparticles synthesized by cannonball leaf extract.

The results of FTIR analysis of this study show different stretches of bonds shown at different peaks; 3432.94-N$\mathrm{H}$ stretch, 2777.28 - single aldehyde, 2676.19-C-H; O-H, 2071.75-C $\equiv \mathrm{C}, 1637.58-\mathrm{C}=\mathrm{C}$, and $1121.56-\mathrm{C}=\mathrm{O}$. Figure 4 shows the peaks near $3440 \mathrm{~cm}^{-1}, 2924 \mathrm{~cm}^{-1}$, and $2854 \mathrm{~cm}^{-1}$ assigned to $\mathrm{OH}$ stretching and aldehydic C-H stretching, respectively. The weaker band at $1629 \mathrm{~cm}^{-1}$ corresponds to amide I arising due to carbonyl stretch in proteins. The peak at $1041 \mathrm{~cm}^{-1}$ corresponds to $\mathrm{C}-\mathrm{N}$ stretching vibration of the amine. The peak near $1741 \mathrm{~cm}^{-1}$ corresponds to $\mathrm{C}=\mathrm{C}$ stretching (nonconjugated). The peak near $833 \mathrm{~cm}^{-1}$ assigned to $\mathrm{C}=\mathrm{CH}_{2}$ and the peaks near $677 \mathrm{~cm}^{-1}$ and $651.96 \mathrm{~cm}^{-1}$ assigned to $\mathrm{CH}$ out of plane bending vibrations are substituted ethylene systems $-\mathrm{CH}=\mathrm{CH}$ (cis) [18]. FTIR spectra of silver nanoparticles exhibited prominent peaks at 2,927, 1,631 , and $1,383 \mathrm{~cm}^{-1}$. The spectra showed sharp and strong absorption band at $1,631 \mathrm{~cm}^{-1}$ assigned to the stretching vibration of $(\mathrm{NH}) \mathrm{C}=\mathrm{O}$ group. The band 1,383 developed for $\mathrm{C}-\mathrm{C}$ and $\mathrm{C}-\mathrm{N}$ stretching; presence of the sharp peak at $2,927 \mathrm{~cm}^{-1}$ was assigned to $\mathrm{C}-\mathrm{H}$ and $\mathrm{C}-\mathrm{H}$ (methoxy compounds) stretching vibration, respectively [22].

The cytotoxic activity of AgNPs synthesized by using cannonball leaf extract was determined by MTT assay (Figure 5). In the present study, the minimum inhibitory concentration $\left(\mathrm{IC}_{50}\right)$ of AgNPs on MCF-7 cells was obtained at $20 \mu \mathrm{L} / \mathrm{mL}$ at 24 hours. Exposure to increasing concentration of AgNPs shows dose-dependent cytotoxicity on MCF-7 cells. Our study correlates with the results of an earlier study [23] where Sapium leaves showed the highest cytotoxic activity against HeLa cell line. Cannonball leaves have also been reported to have antioxidant activity, and this may have a role to play in the observed activity in the cancer cell lines as antioxidants play a complex role in cancer prevention [24]. 


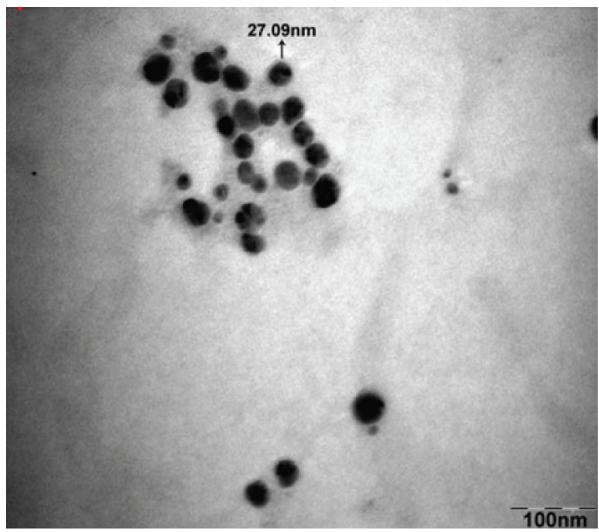

(a)

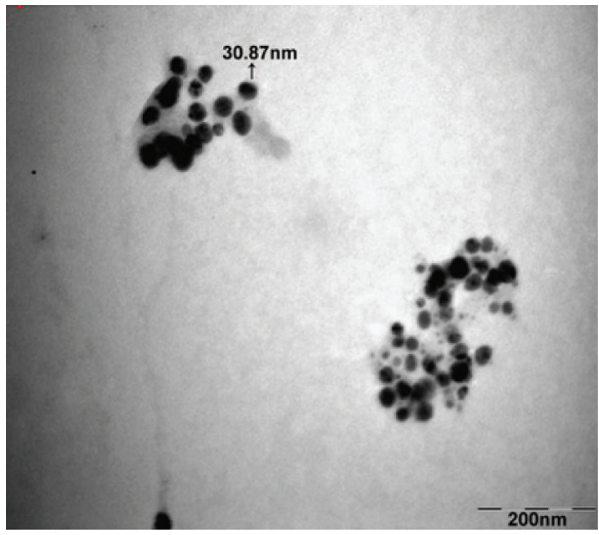

(c)

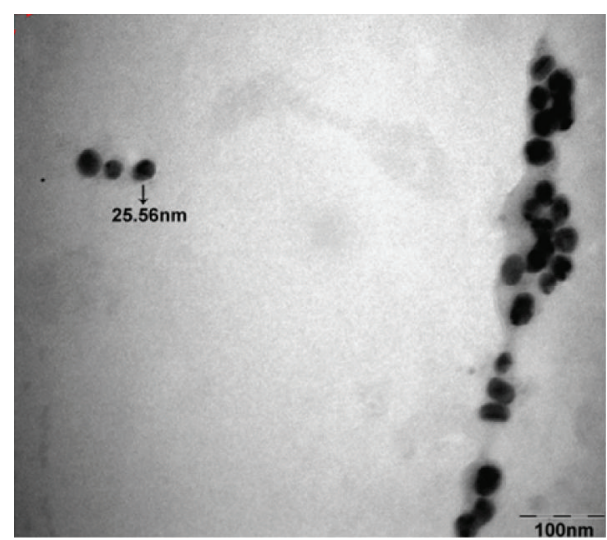

(b)

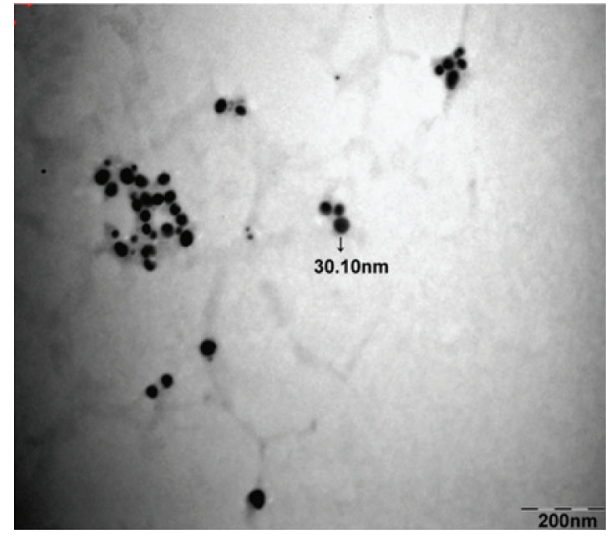

(d)

Figure 3: Transmission electron microscopy images of AgNPs at different magnification levels ((a) and (b) - 100 nm; (c) and (d) - 200 nm).

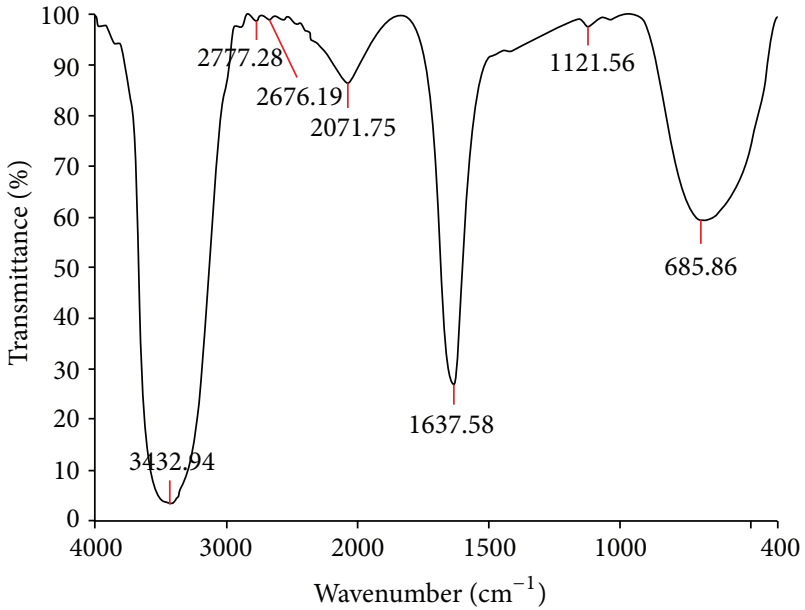

FIGURE 4: FTIR spectra of cannonball leaf extract.

\section{Conclusions}

In conclusion, there has been an exponentially increasing interest in biological synthesis of AgNPs. In this study, AgNPs were synthesized by an ecofriendly and convenient method using cannonball leaf extract at ambient temperature.

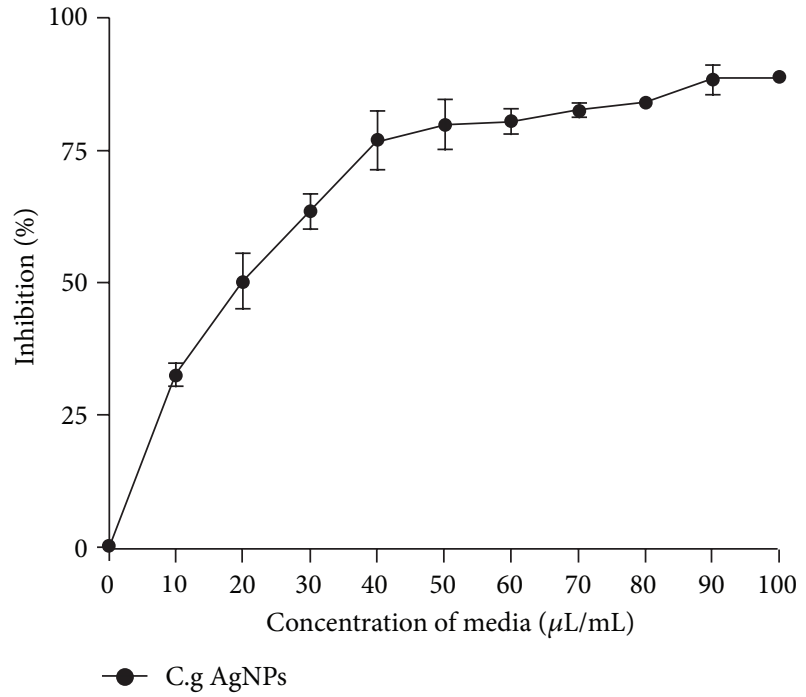

FIGURE 5: Cytotoxicity of synthesized AgNPs on MCF-7cells.

Cannonball leaf extract has been used as a reducing agent for the synthesis of silver nitrate into silver nanoparticles. Green synthesized silver nanoparticles are confirmed by color change which was monitored quantitatively by UV-Vis 
spectroscopy at $440 \mathrm{~nm}$. Further characterization with SEM and TEM analysis shows the spherical, polydisperse AgNPs of particle size ranging from 5 to $35 \mathrm{~nm}$ with an average size of $28.40 \mathrm{~nm}$. FTIR showed the structure, the respective bands of the synthesized nanoparticles, and the stretch of bonds. The cytotoxicity analysis of the green synthesized silver nanoparticles was observed that it inhibits the MCF7 breast cancer cell line. However, further investigations were needed to identify the scaling-up usage of this extract on metallic nanoparticle synthesis and its applications on anticancer therapy.

\section{Acknowledgments}

The authors would like to acknowledge their dear colleagues for their support rendered. The authors extend their heartfelt regards to the management and Director of Faculty of Science Humanities, SRM University, for their constant support throughout the research work. The authors extend their indebted thanks to TANUVAS for the help rendered in microscopic characterization.

\section{References}

[1] P. U. Sanjay, K. N. Jayaveera, C. K. Ashock Kumar, and G. S. Kumar, "Antimicrobial, wound healing and antioxidant potential of Couroupita guianensis in rats," Pharmacologyonline, vol. 3, no. 6, pp. 269-281, 2007.

[2] M. M. G. Pinheiro, S. O. Bessa, C. E. Fingolo et al., "Antinociceptive activity of fractions from Couroupita guianensis Aubl. leaves," Journal of Ethnopharmacology, vol. 127, no. 2, pp. 407413, 2010.

[3] C. Castelluccio, G. Paganga, N. Melikian et al., "Antioxidant potential of intermediates in phenylpropanoid metabolism in higher plants," FEBS Letters, vol. 368, no. 1, pp. 188-192, 1995.

[4] F. Aqil, I. Ahmad, and Z. Mehmood, "Antioxidant and free radical scavenging properties of twelve traditionally used Indian medicinal plants," Turkish Journal of Biology, vol. 30, no. 3, pp. 177-183, 2006.

[5] V. Rajamanickam, A. Rajasekaran, S. Darlin Quine et al., "Anthelmintic activity of the flower extract of Couroupita guianensis," The Internet Journal of Alternative Medicine, vol. 8, no. 1, pp. 107-111, 2009.

[6] R. P. Feynman, "There's plenty of room at the bottom," Science, vol. 254, no. 5036, pp. 1300-1301, 1991.

[7] J. Huang, Q. Li, D. Sun et al., "Biosynthesis of silver and gold nanoparticles by novel sundried Cinnamomum camphora leaf," Nanotechnology, vol. 18, no. 10, Article ID 105104, 2007.

[8] P. Mukherjee, A. Ahmad, D. Mandal et al., "Fungus-mediated synthesis of silver nanoparticles and their immobilization in the mycelial matrix: a novel biological approach to nanoparticle synthesis," Nano Letters, vol. 1, no. 10, pp. 515-519, 2001.

[9] T. Klaus-Joerger, R. Joerger, E. Olsson, and C. G. Granqvist, "Bacteria as workers in the living factory: metal-accumulating bacteria and their potential for materials science," Trends in Biotechnology, vol. 19, no. 1, pp. 15-20, 2001.

[10] N. Saifuddin, C. W. Wong, and A. A. N. Yasumira, "Rapid biosynthesis of silver nanoparticles using culture supernatant of bacteria with microwave irradiation," E-Journal of Chemistry, vol. 6, no. 1, pp. 61-70, 2009.
[11] M. Kowshik, S. Ashtaputre, S. Kharrazi et al., "Extracellular synthesis of silver nanoparticles by a silver-tolerant yeast strain MKY3," Nanotechnology, vol. 14, no. 1, pp. 95-100, 2003.

[12] S. Minaeian, A. R. Shahverdi, A. S. Nohi, and H. R. Shahverdi, "Extracellular biosynthesis of silver nanoparticles by some bacteria," Journal of Sciences Islamic Azad University, vol. 17, no. 66, pp. 1-4, 2008.

[13] S. Karthick Raja, S. Ganesh, and Avimanyu, "Evaluation of antibacterial activity of silver nanoparticles synthesized from Candida glabrata and Fusarium oxysporum," International Journal of Medicobiological Research, vol. 1, no. 3, pp. 130-136, 2011.

[14] T. Mosmann, "Rapid colorimetric assay for cellular growth and survival: application to proliferation and cytotoxicity assays," Journal of Immunological Methods, vol. 65, no. 1-2, pp. 55-63, 1983.

[15] P. Mulvaney, "Surface plasmon spectroscopy of nanosized metal particles," Langmuir, vol. 12, no. 3, pp. 788-800, 1996.

[16] K. Govindaraju, S. Tamilselvan, V. Kiruthiga, and G. Singaravelu, "Biogenic silver nanoparticles by Solanum torvum and their promising antimicrobial activity," Journal of Biopesticides, vol. 3, no. 1, pp. 394-399, 2010.

[17] G. Thirumurugan and M. D. Dhanaraju, "Novel biogenic metal nanoparticles for pharmaceutical applications," Advanced Science Letters, vol. 4, no. 2, pp. 339-348, 2011.

[18] A. M. Priya, R. K. Selvan, B. Senthilkumar, M. K. Satheeshkumar, and C. Sanjeeviraja, "Synthesis and characterization of $\mathrm{CdWO}_{4}$ nanocrystals," Ceramics International, vol. 37, no. 7, pp. 2485-2488, 2011.

[19] J. Kasthuri, K. Kathiravan, and N. Rajendiran, "Phyllanthinassisted biosynthesis of silver and gold nanoparticles: a novel biological approach," Journal of Nanoparticle Research, vol. 11, no. 5, pp. 1075-1085, 2009.

[20] R. Kavitha, P. Kamalakannan, S. Sridhar et al., "In vitro antimicrobial activity and phytochemical analysis of Indian medicinal plant Couroupita guianensis Aubl," Journal of Chemical Pharmaceutical Research, vol. 3, no. 6, pp. 115-121, 2011.

[21] M. Juvekar, A. Juvekar, M. Kulkarni et al., "Phytochemical and pharmacological studies on the leaves of Couroupita guianensis Aubl," Planta Medica, vol. 75, p. PJ168, 2009.

[22] S. Marimuthu, A. A. Rahuman, G. Rajakumar et al., "Evaluation of green synthesized silver nanoparticles against parasites," Parasitology Research, vol. 108, no. 6, pp. 1541-1549, 2011.

[23] A. Sowemimo, M. van de Venter, L. Baatjies, and T. Koekemoer, "Cytotoxic activity of selected Nigerian plants," African Journal of Traditional, Complementary and Alternative Medicines, vol. 6, no. 4, pp. 526-528, 2009.

[24] A. Martínez, E. Conde, A. Moure, H. Domnguez, and R. J. Estévez, "Protective effect against oxygen reactive species and skin fibroblast stimulation of Couroupita guianensis leaf extracts," Natural Product Research, vol. 26, no. 4, pp. 314-322, 2012. 

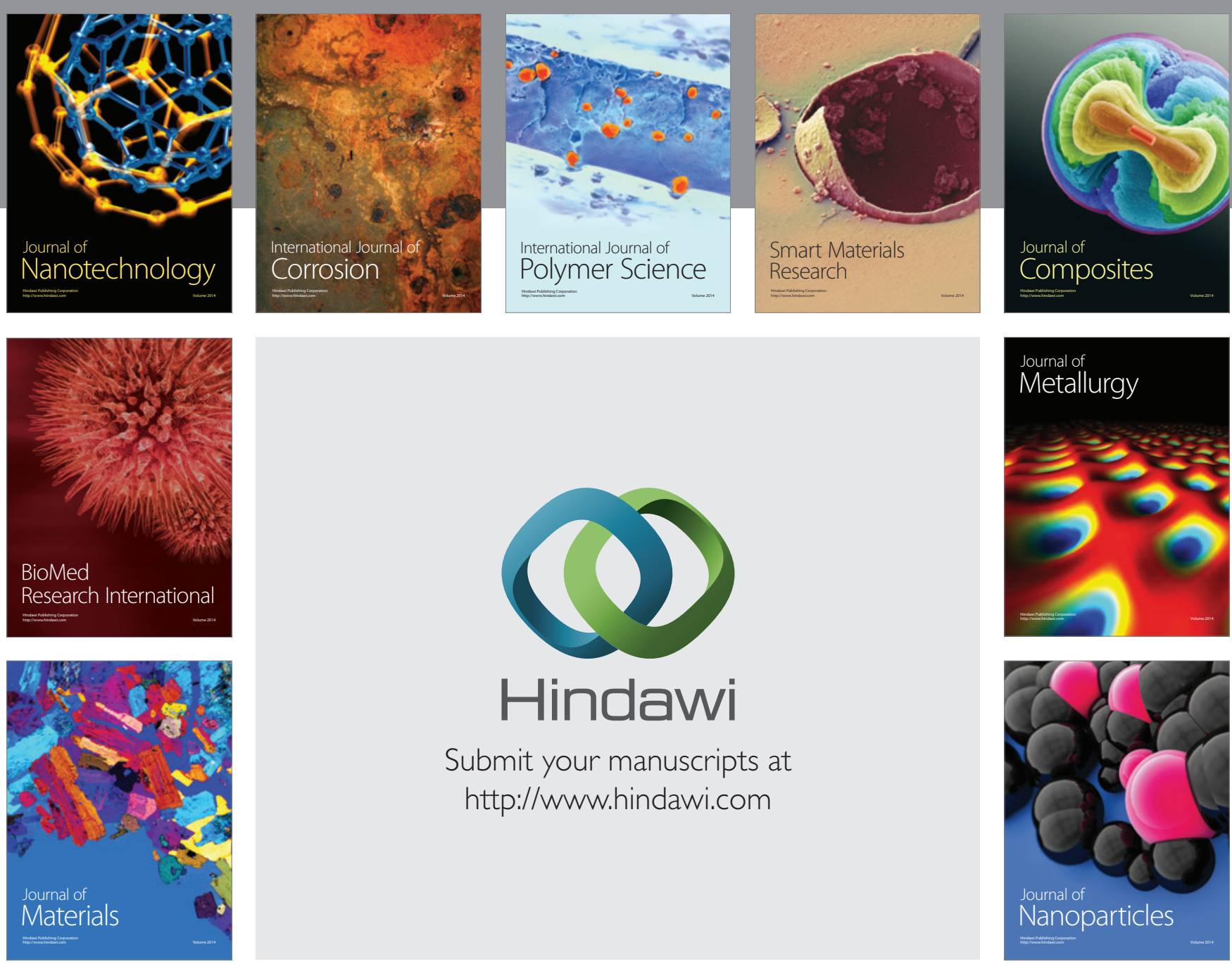

Submit your manuscripts at http://www.hindawi.com
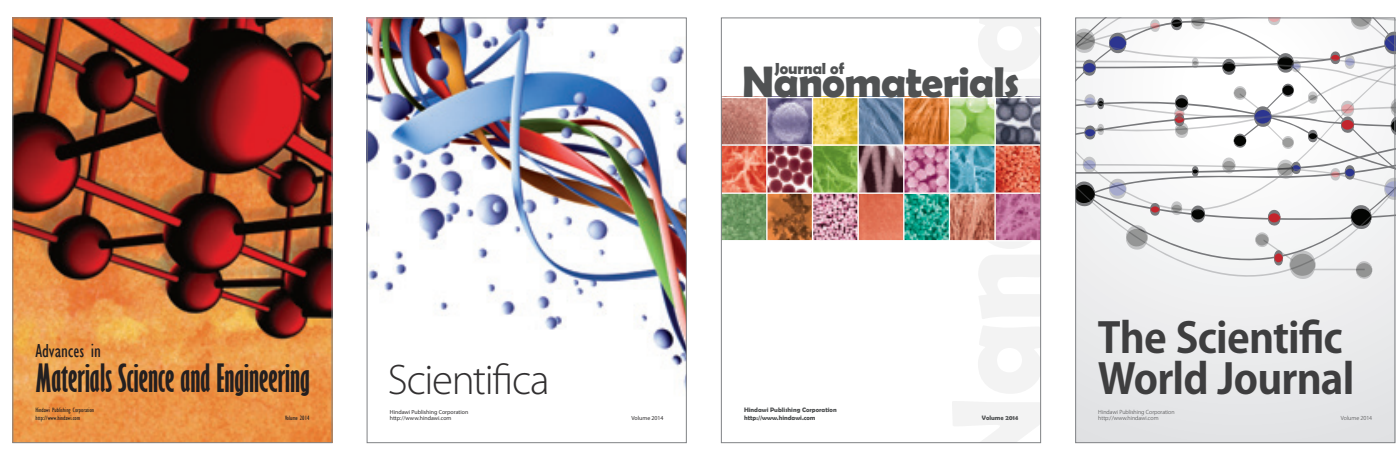

\section{The Scientific World Journal}
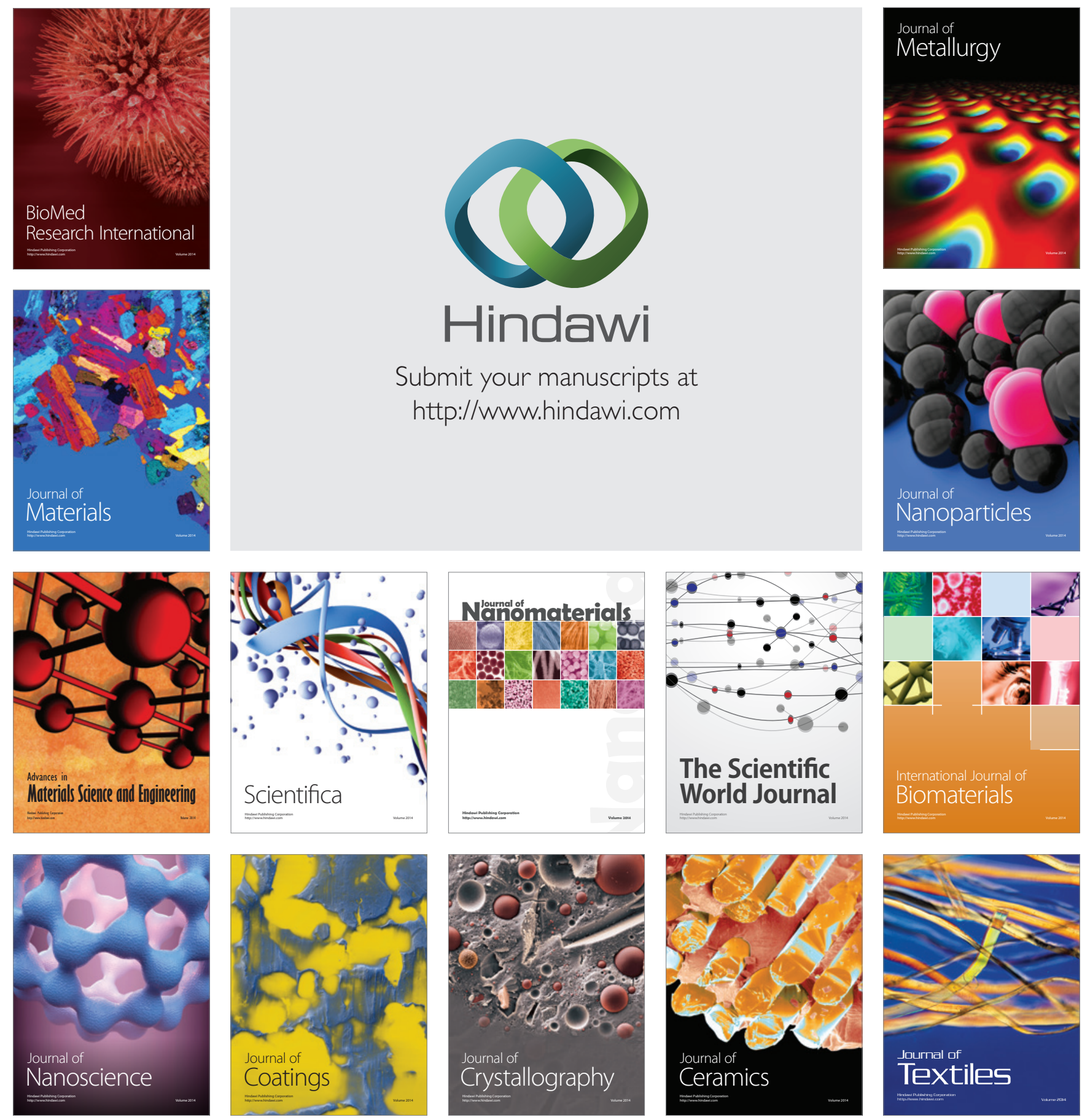